and increased portal pressure has been found, even in the absence of portal vein thrombosis. Datta et al. (1975) compared their results from patients with chronic myeloid leukaemia with those from patients with tropical splenomegaly and concluded that splenomegaly and increased portal flow were by themselves insufficient to explain the hypertension. They postulated that sinusoidal infiltrations by leukaemic cells-which they found in liver biopsies from all their cases-were a major contributory factor by increasing resistance to the flow. The findings in the present patient appeared to be unique, differing from those previously reported in that the portal hypertension was clinically overt and postmortem examination revealed disturbances in hepatic architecture, other than infiltrations, sufficient to explain the clinical picture. Two needle biopsies during life failed to demonstrate these changes. This suggests that the cause of portal hypertension in myeloid leukaemia may not be as simple as previously thought and the full picture may only become complete when sufficient post-mortem studies are carried out.

The nature of the changes is complex and their pathogenesis obscure. The presence of anisocytosis in the liver and lung raises the possibility of busulphan toxicity as a contributory factor. The nodu- larity without diffuse fibrosis vaguely resembled that seen in Felty's syndrome (Blendis et al., 1970a). The cholestasis appeared to be related to disturbances in hepatic architecture and there was no evidence of extrahepatic obstruction nor relationship between the development of jaundice and the low-dosage short-term administration of chlorpropamide, a drug known to cause sensitivity cholestasis.

\section{Acknowledgments}

We thank Dr I. M. Murray Lyon and his staff who helped with the management of the hepatic complication in this patient and Dr G. D. Pegrum who helped with the general management.

\section{References}

Blendis, L.M., Ansell, I.D., Lloyd Jones, K., Hamilton, E. \& Williams, R. (1970a) Liver in Felty's syndrome. British Medical Journal, 1, 131.

Blendis, L.M., Banks, D.C., Ramboer, C. \& Williams, R. (1970b) Spleen blood flow and splanchnic haemodynamics in blood dyscrasia and other splenomegalies. Clinical Science, 38, 73.

DatTa, D.V., Grover, S.L., Saini, V.K., Datta, B.N., Aikat, B.K \& Chhuttani, P.N. (1975) Portal hypertension in chronic leukaemia British Journal of Haematology, 31, 279.

Shaldon, S. \& Sherlock, S. (1962) Portal hypertension in the myeloproliferative syndrome and the reticuloses. American Journal of Medicine, 32, 759.

\title{
Gynaecomastia associated with gonadotrophin-secreting carcinoma of the lung
}

\author{
D. FAIRLAMB \\ M.B., B.S.
}

\author{
EVELYN BOESEN \\ M.D. (London)
}

The Royal Free Hospital, Pond Street, Hampstead, London, NW3

\begin{abstract}
Summary
A 67-year-old man developed dermatomyositis. Investigation revealed an oat cell carcinoma of the lung. When he developed unilateral gynaecomastia this tumour was found to secrete gonadotrophins. The gynaecomastia disappeared after treatment with an anti-oestrogen-tamoxifen. This use of tamoxifen has not previously been described. Partial tumour regression was obtained with several cytotoxic drug regimes. His dermatomyositis responded to this treatment and remains in remission.
\end{abstract}

\section{Case report}

A 67-year-old Caucasian male was admitted in March 1975 for investigation of a rash which had been present for 3 months. He was a semi-retired pastry cook who had smoked ten cigarettes daily all his life. The pruritic rash had started on his hands and spread centrally. There was no previous history of skin disease or other significant illness. He also had generalized weakness, particularly affecting his grip. He had been extensively investigated at another hospital 1 year previously for anorexia and weight- 
loss for which no cause could be found. He was treated with Panadeine Co. and phenylbutazone for presumed osteoarthritis (both these drugs were stopped when his rash appeared) and steroid creams and chlorpheniramine were started when the pruritic rash began. His alcohol consumption was an occasional whisky. The rash was typical of dermatomyositis with its characteristic 'linear distribution' and affected his hands, arms, knees, shoulders, chest, neck and face. He had enlarged nodes in the left axilla. There was wasting of the scapula muscles and weakness of proximal and distal muscles in all four limbs. Vibration, joint position and light touch sensations were all impaired especially in the lower limbs. Other positive findings were a liver enlarged $2 \mathrm{~cm}$ below the costal margin, a moderately enlarged prostate and some scattered rhonchi in his chest. His genitalia were normal. There was no finger or toe clubbing.

\section{Investigations}

$\mathrm{Hb}, 12.8 \mathrm{~g} / \mathrm{dl}$; ESR (Westergren) $48 \mathrm{~mm} / \mathrm{hr}$. Chest X-ray showed a prominent left hilum. Chest tomography suggested a carcinoma with cavitation. Bronchoscopy confirmed the presence of a tumour of the left upper lobe bronchus. Histology of a biopsy specimen from this tumour was that of an oat cell carcinoma. Liver scan was suggestive of hepatic metastases. Liver function tests, barium meal, intravenous pyelography and pulmonary function tests were all normal. Creatine phosphokinase 17 i.u./l. Electromyography confirmed the presence of a proximal myopathy with a peripheral neuropathy. Hand and wrist X-rays revealed no radiological evidence of hypertrophic pulmonary osteoarthropathy.

\section{Progress}

He was treated initially with vincristine (VCR), 5fluorouracil and cyclophosphamide as a bolus to accompany a high dose methotrexate infusion given over $14 \mathrm{hr}$, with folinic acid rescue. This was repeated every 3 weeks. VCR was omitted after the second dose because of a worsening neuropathy. The patient's response to therapy was assessed by monitoring his weight and symptoms, the chest X-ray, axillary nodes, liver size and dermatomyositis. The dermatomyositis, unaffected by steroids, responded dramatically and the pruritus was abolished after the first course of drugs. He lost $3.5 \mathrm{~kg}$ over the following 6 months. His liver size and chest X-ray were little changed with therapy. The axillary nodes completely regressed. After 5 months' therapy he had relapsed as judged by enlarging axillary nodes-all other parameters were unchanged. Doxorubicin given every 3 weeks was then substituted for the previous chemotherapy. Before being given his first dose of doxorubicin he developed tenderness of the left chest wall. The nipple was normal but there was a tender subareolar mass $2 \times 2 \mathrm{~cm}$. The right nipple area was normal. Clinically he had unilateral gynaecomastia. Serum gonadotrophins were: luteinizing hormone (LH) $10.2 \mathrm{u} . / 1$ (normal range 1.5-10.0 u./1 in males) and follicle stimulating hormone (FSH) $6.9 \mathrm{u} . / 1$ (normal range in males $0.4-2.0 \mathrm{u}$./1). Serum oestradiol $116 \mathrm{pg} / \mathrm{ml}$ (normal range in males $15-40 \mathrm{pg} / \mathrm{ml}$ ). He was started on an anti-oestrogen, tamoxifen $10 \mathrm{mg}$ t.d.s. After 2 weeks' therapy the mass had disappeared. The nodes regressed with doxorubicin but remain palpable. Repeat oestradiol and gonadotrophins, whilst still on tamoxifen and after two doses of doxorubicin, were: oestradiol $170 \mathrm{pg} / \mathrm{ml}$; LH $21.7 \mathrm{u} . / 1$; FSH $11.2 \mathrm{u} . / 1$. At the time of writing he is still in partial remission although his nodes remain palpable. The dermatomyositis and gynaecomastia are still under control. There has been no improvement in his weakness and he is still slowly losing weight.

\section{Discussion}

Gynaecomastia has been reported in association with lung cancer and raised serum gonadotrophins by several authors (Fusco and Rosen, 1966; Cottrell et al., 1969). The histology of these tumours is usually anaplastic large cell carcinoma but Cottrell et al. (1969) reported cases of squamous cell, adenocarcinoma and oat cell carcinoma. The origin of the gonadotrophins has been ascribed to tumour cells. Assay of tumour tissue (Dailey and Marcuse, 1969) hormone location by immunofluorescence (Becker et al., 1968) and arteriovenous difference of hormone levels across the tumour bed (Faiman et al., 1967) seem to support this. The origin of the raised serum oestrogen is less clear. It has been suggested that testicular and adrenal stimulation by the circulatory gonadotrophins is responsible (Fusco and Rosen, 1966; Cottrell et al., 1969), but Kirschner, Cohen and Jespersen (1974) raised the possibility that the tumour itself released oestrogens. Whether gynaecomastia develops directly as a result of the tumour secreting oestrogens, gonadotrophins, androgens or thyroid hormones or through hormones elaborated by secondary stimulation of end organs is speculative (Bannayan and Hajdu, 1972; Treves, 1958). This patient had no clinical evidence to suggest elaboration of other hormones.

In a series of patients with bronchogenic carcinoma, half of whom had gynaecomastia, there was no difference in oestrogen secretion between the two groups (Ginsburg, 1969). One might expect gynaecomastia to be bilateral but Hamer (1975) reports that in over $75 \%$ of cases the condition is unilateral; the left breast being affected more often than the right; this is reported elsewhere (Bannayan and Hajdu, 1972). 
Gynaecomastia is known to be associated with drugs (Meyler and Herxheimer, 1972). The only such drug taken by the patient was vincristine (Smith and Barrett, 1967). The association with this drug has only been reported once and is unconfirmed. In the present patient the vincristine was discontinued 15 weeks before his gynaecomastia developed.

Tamoxifen is an anti-oestrogen. This agent has been shown in rats to oppose the effects of exogenously administered oestrogen (Prasad and Sarkaran, 1972; Cole, Jones and Todd, 1971). This is thought to be due to competition for oestrogenbinding sites in end organs. Gonadotrophin levels are unaffected. In man, anti-oestrogens have been used to interrupt the pituitary-ovarian axis and to produce regression in advanced breast cancer (Cole et al., 1971; Ward, 1973; Bloom and Boesen, 1974).

The association of dermatomyositis with malignancy is well known (Grace and Dao, 1959; Brunner and Lobraico, 1951) and has been reviewed by Williams (1959) and Arundell, Wilkinson and Haserick (1960). The treatment of dermatomyositis with immunosuppressives is also well documented (Sokoloff, Goldberg and Pearson, 1971; Malaviya, Many and Schwartz, 1968; Metzger et al., 1974). The present patient's dermatomyositis did not recur when methotrexate was discontinued and adriamycin substituted.

\section{Conclusion}

This patient had an oat cell carcinoma of the lung, raised setum gonadotrophins and raised serum oestrogens. He developed gynaecomastia whilst on cytotoxic drug therapy. The tumour itself only partially regressed with treatment. Liver function tests have never been abnormal and the liver size has remained constant. The gynaecomastia regressed completely on tamoxifen despite rising oestrogen and gonadotrophin levels. The dermatomyositis remitted on methotrexate and did not recur when doxorubicin was substituted. Symptomatic relief of unpleasant clinical features was achieved.

\section{References}

ARUndell, F.D., Wilkinson, R.D. \& HASERiCK, J.R. (1960) Dermatomyositis and malignancy in adults. A survey of twenty years' experience. Archives of Dermatology, 82, 722.

BanNayan, G.A. \& HaJdu, S.I. (1972) Gynecomastia: clinicopathological study of 351 cases. American Journal of Clinical Pathology, 57, 431.
Becker, K.L., Cottrell, J., Moore, C.F., Winnaker, J.L., MatthewS, M.J. \& KaTZ, S. (1968) Endocrine studies in a patient with gonadotrophin secreting bronchogenic carcinoma. Journal of Clinical Endocrinology and Metabolism, 28, 809.

Bloom, H.J.G. \& Boesen, E. (1974) Anti-oestrogens in treatment of breast cancer: value of nafoxidine in 52 advanced cases. British Medical Journal, $2,7$.

BrunNer, M.J. \& LobRAICO, R.V. (1951) Dermatomyositis as an index of malignant neoplasm: report of case and review of literature. Annals of Internal Medicine, 34, 1269.

COLE, M.P., Jones, C.T.A. \& TodD, I.D.H. (1971) A new anti-oestrogenic agent in late breast cancer. A clinical appraisal of I.C.I. 46474. British Journal of Cancer, 25, 270.

Cottrell, J.C., Becker, K.L., Matthews, M.J. \& Moore, C.F. (1969) The histology of gonadotrophin secreting carcinoma. American Journal of Clinical Pathology, 52, 720.

Dailey, J.E. \& MARCuSE, P.M. (1969) Gonadotrophin secreting giant-cell carcinoma of the lung. Cancer, 24, 388.

Faiman, C., Colwell, J.A., Ryan, R.J., Hershman, J.M. \& SHIELDS, T.W. (1967) Gonadotrophin secretion from a bronchogenic carcinoma. New England Journal of Medicine, 277, 1395.

Fusco, F.D. \& Rosen, S.W. (1966) Gonadotrophin-producing anaplastic large cell carcinoma of the lung. New England Journal of Medicine, 275, 507.

Ginsberg, J. (1969) Gynaecomastia. Practitioner, 203, 166.

GRACE, J.T. \& DAO, T.L. (1959) Dermatomyositis in cancer: a possible aetiological mechanism. Cancer. New York, Philadelphia, etc., 12, 648.

HAMER, D.B. (1975) Gynaecomastia. British Journal of Surgery, 62, 326.

Kirschner, M.A., Cohen, F.B. \& Jespersen, D. (1974) Oestrogen production and its origin in men with gonadotrophin producing neoplasms. Journal of Clinical Endocrinology and Metabolism, 29, 112.

Malaviya, A.N., Many, A. \& Schwartz, R.S. (1968) Treatment of dermatomyositis with Methotrexate. Lancet, ii, 485.

Metzger, A.L., Bohan, A., Goldberg, L.S., Bluestone, R. \& Pearson, C.M. (1974) Polymyositis and dermatomyositis: combined methotrexate and corticosteroid therapy. Annals of Internal Medicine, 81, 182.

Meyler, L. \& HerXheimer, A. (Editors) (1972) Side Effects of Drugs, Vol. VII. Excepta Medica, Amsterdam.

Prasad, M.R.N. \& Sarkaran, M.S. (1972) Mode of action of non-steroidal anti-oestrogens. Acta endocrinologica (Suppl.), 166, 448.

SMith, R.M. \& BARRETT, O. (1967) Gynecomastia associated with vincristine therapy. California Medicine, 107, 347.

Sokoloff, M.C., Goldberg, L.S. \& Pearson, C.M. (1971) Treatment of corticosteroid-resistant polymyositis with methotrexate. Lancet, i, 14.

Treves, N. (1958) Gynecomastia. Cancer, New York, Philadelphia, etc., 11, 1083.

WARD, H.W.C. (1973) Anti-oestrogen therapy for breast cancer: a trial of tamoxifen at two different dose levels. British Medical Journal, 1, 14.

Williams, R.C. (1959) Dermatomyositis and malignancy: a review of the literature. Annals of Internal Medicine, 50, 1174. 